\title{
Transições canceladas: teatro e experiência no Brasil (notas para um programa de trabalho)
}

Canceled transitions: theater and experience in Brazil (notes for a work program)

José Fernando de Azevedo

José Fernando de Azevedo Professor da Escola de Arte Dramática da Escola de Comunicações e Artes da Universidade de São Paulo. Diretor e dramaturgo do Teatro de Narradores.






\section{Resumo}

Recorrente nos títulos da maior parte das obras clássicas de interpretação da vida cultural e social no Brasil, a ideia de formação nunca se estabeleceu como modelo de compreensão do teatro entre nós. Sinal de uma experiência feita toda de cancelamentos, essa ausência ou insuficiência impõe outras exigências interpretativas. Das relações entre forma social e forma estética, certamente emerge a experiência teatral, entre nós, como depoimento acerca do tempo presente, na ordem de um teatro mundial - desde a colônia, se quisermos, aos diversos estágios do capitalismo e seus desenvolvimentos.

Palavras-chave: Formação, Passado, História, Esquecimento, Apagamento.

\section{Abstract}

Recurrent in most classical titles on interpretation about cultural and social life in Brazil, the idea of formation has never settled as a model for our comprehension on theater. Signal of an experience founded by a series of cancellations, this absence or insufficiency imposes other interpretative demands. From the relations between social and esthetic form certainly emerges among us the theatrical experience as an evidence on the times, in terms of worldwide theater - since colony, we might say, and the several stages of capitalism and its developments.

Keywords: Formation, Past, History, Oblivion, Cancellation.

No palco há bonecos de negros e animais, que serão maltratados de várias maneiras, conforme as circunstâncias. Há, também, um espelho.

As cenas são separadas por segundos de escuridão. Nesta peça tudo é questão de ritmo e corte, pois ela é construída sobre transições canceladas. A passagem da chanchada à atrocidade, as conversões rapidíssimas e reversíveis em matéria de convicção, a brevidade com que se dispõe de uma discurseira, a alternância de asneira e cinismo devem fazer figura de História contemporânea.

(Roberto Schwarz, A lata de lixo da história) 
A perspectiva da formação ${ }^{1}$ nunca se estabeleceu como modelo de interpretação da experiência do teatro no Brasil. Em 1964, no prefácio programático de seu Teatro em progresso, Décio de Almeida Prado esboçava as seguintes coordenadas:

A poesia e o romance brasileiro da fase propriamente modernista, por exemplo, alcançaram por vezes plenamente seus objetivos. Dentro das perspectivas estéticas que eram as suas, realizaram-se com perfeição. Podemos atribuir-lhes maior ou menor valor, conforme as nossas preferências, pessoais ou de escola, mas não lhes negar o caráter de obras acabadas, completas, prontas para entrar na história. Ora, é essa plenitude, embora relativa, que buscaríamos em vão no moderno teatro brasileiro. Para todos os efeitos, ele permanece ainda a work in progress. (PRADO, 1964, p. 7)

Já em 1988, em seu Teatro brasileiro moderno, o crítico abandonava qualquer aposta naquela direção. Sendo o momento agora de uma "possivelmente benéfica democratização da cultura", face à diversidade das práticas:

A multiplicação pode ser vista, portanto, também como divisão: teatrinhos cada vez menores, textos de um ou dois atores, produção pobre, público reduzido etc. Se nos tempos heroicos do amadorismo teatral, sofremos, conforme ficou consignado, de um certo complexo de inferioridade que nos inibia de escrever ou dirigir peças, esmagados que estávamos pela superioridade estrangeira, encontramo-nos ao que tudo indica na situação inversa. À medida que cresce o culto da chamada criatividade (a ideia de que qualquer um, vencidos os seus bloqueios, é capaz de dar origem a uma obra de arte, ainda que modesta, valendo mais esse desenvolvimento da personalidade que considerações de ordem técnica ou estética), alarga-se o círculo de pessoas que se julgam habilitadas a tentar o teatro. Se a questão é de espontaneidade, de liberação de impulso, não de vocação ou de aprendizado, por que não eu?

Ainda uma vez, o que inexiste para disciplinar esta possivelmente benéfica democratização da cultura, convertendo a quantidade em qualidade, é uma doutrina central, um padrão de julgamento (que tornava outrora a crítica tão mais fácil), uma visão unitária a respeito da natureza e da função do teatro, que possa aglutinar e organizar o esforço coletivo. (PRADO, 1988, p. 140-141)

1 Este texto corresponde a um programa de trabalho, em andamento. Uma versão preliminar, com algumas das notas aqui apresentadas, foi publicada na revista Trema, n. 8, Recife, 2016. 
"Work in progress" cujo progresso redundava num inacabamento renitente, o teatro permanece tarefa inconclusa, relativamente amadora, à medida que ali, onde se reclamou sua profissionalização, esta não se esboçou sem a generalizada precarização do trabalho. A nota em tom menor registrava uma espécie de coroamento de um processo que vinha desde os anos 1940, cifrado pelo empenho de um "modernismo teatral" que, segundo Décio, não escondia seu "repúdio ao passado" (Ibid., p. 137). Ironizando as "ilusões louvavelmente patrióticas", seu comentário não portava maior entusiasmo cosmopolita, seguindo talvez a intuição de que o teatro trazia já as marcas de uma desintegração da perspectiva nacional, em parte, mas sem horizonte evidente de integração de qualquer outra parte ao futuro - local ou global.

Teatro moderno e repúdio ao passado: um repúdio aparentemente paradoxal, uma vez que, na prática, tudo se passa emblematicamente entre 1964 e 1988, como se algo permanecesse, ou como se as mudanças nos devolvessem àquilo que o empenho modernizante propunha superar. Tratou-se de modernização, sem dúvida; conservadora, todavia. Repúdio, nesse caso, configura esquecimento como processo.

Em 1988, Décio falava de "frustrações do presente". Mas a experiência do tempo presente não é homogênea: em grande medida, o passado não é aquilo que passou, mas algo que permanece não resolvido, a travar nossas expectativas de futuro. Aquele repúdio do passado é sem dúvida a marca-fantasia de uma reposição constante do mesmo passado. As demandas de esquecimento que pressionam a cultura são, a depender de quem demanda, ora exigências de superação, ora práticas de apagamento. Quem esquece corre sempre o risco de lembrar; mas há coisas que ainda não podemos esquecer.

O teatro não escapa a essas demandas, nem à experiência do tempo, antes, implica um trabalho sobre as temporalidades que nos atravessam, e que atravessamos. Em cena, ainda convocamos fantasmas, quando não somos por eles convocados. Sendo, todavia, uma arte de vivos para vivos, esse convívio com os mortos alerta a audiência: o decisivo está sempre fora de cena; mais do que aquilo que vemos, importa o que ela nos faz imaginar. 
Há, sem dúvida, o problema da efemeridade da cena. Mas esta não é uma questão meramente epistemológica, ou antes, precisamente por sê-lo, é sobretudo uma questão política (como nos faz ver, em algum lugar, o antropólogo Eduardo Viveiros de Castro). O teatro deve habitar a memória de quem fez e viu - portanto, importa saber quem faz e quem vê. Só no encontro entre as partes é que se pode discutir sobre aquilo que é feito e aquilo que é visto - o modo como é feito e visto.

É possível que uma outra história do teatro brasileiro fosse antes uma história do esquecimento. O teatro, aliás, traz, já em sua certidão de nascimento, marcas de um apagamento reiterado. Da cena de um Gonçalves Magalhães, por exemplo, insistia-se sobre a emergência do "assunto nacional." Mas visto a contrapelo, que assunto seria esse senão o fato de que a "independência da nação" não superava a situação de colônia? Tanto mais, quando a escravidão, apagada da cena, não alarmava uma plateia de proprietários de escravos.

Em perspectiva, fazer a história do teatro a partir de suas tentativas de modernização, ou seus turning points (o que levará à ideologia do "teatro brasileiro moderno": desde Os comediantes/Nelson Rodrigues, EAD/TBC, Arena, Oficina até os encenadores dos anos 1980 - para ficar no fuso Rio-São Paulo), implicou negligenciar: a) o teatro brasileiro não é apenas uma extensão do teatro europeu, mas é moderno no mesmo sentido em que se pode afirmar moderna a colonização enquanto expansão do capitalismo; b) as insuficiências desse teatro revelam não apenas as dificuldades de um processo de aclimatação de temas e formas, mas também antecipam limites desse processo quando nos devolvem ao modelo e à sua impossibilidade de universalização - a escravidão negra é uma invenção daquela modernidade; c) a história do teatro é não apenas a história de endereçamentos e encontros, mas sobretudo a história de tensões que levam a alianças de imaginação (cena e público), vínculos que são sempre de classe; d) trata-se de uma cena, em mais de um sentido, crioula: por conta da língua que emerge das práticas de miscigenação, das sobrevivências dos extermínios indígena e negro ainda operantes, da consciência-levante de um racismo tão dissimulado quanto estruturante de nossa sociabilidade, e da redução de diferenças em desigualdades, além da fisionomia própria de presenças até então apagadas da cena e as formas 
possíveis de sua elaboração; e) a crítica da ordem patriarcal supressiva é não apenas o pressuposto dessa história, mas está posta a exigência de ver, de perto, no depoimento das formas, as suas marcas; também agora, quando o negro, a mulher, o índio, os movimentos sociais, LGBT, imigrantes e as chamadas "minorias" ensaiam coros, testemunhos de uma luta que emergem, contemporâneos entre si, como ocupantes de uma cena que sempre os figurou - ou negou - como invasores; f) mais que uma perspectiva pós-colonial, trata-se de um empenho anticolonial.

Não é possível fazer teatro hoje sem refazer a história desse teatro.

Aquilo que se convencionou chamar teatro de grupo no Brasil, pelo menos desde o fim dos anos 1990 e durante a década de 2000, resultou de um movimento não premeditado, que trouxe para a cena, por razões inscritas no próprio movimento, aspectos de um processo a um só tempo de desmanche e de reconfiguração de estruturas e dinâmicas da sociedade brasileira, no qual a cena estava inscrita, fazendo, daquele processo, a crônica, sem deixar de ser dele um sintoma. Menos um programa que uma situação, portanto, forjava-se aí uma outra imaginação, e uma espécie de comunidade de grupos, tão provisória quanto a matéria que a alimentava. Até onde essa comunidade se excedia e se comunicava com outras, ou apenas as presumia, é algo ainda a se verificar.

Esse teatro se definiu, sem dúvida, por formas específicas de produção, desde a sua relação com os materiais, a invenção ou reposição refletida de procedimentos, as práticas de organização do trabalho, mas também por se deixar inscrever numa continuidade relativa, determinada por uma espécie de resiliência dos processos e alguns programas, marcados, no entanto, por uma intermitência econômica - esta já uma espécie de antecipação dos limites da euforia inclusiva que tomaria conta do país nos anos mais recentes.

Continuidade relativa, por um lado; antecipação de limites, por outro, quando as formas de interrupção foram sempre ensaiadas (política e economicamente). Quer dizer: a crise é um modelo de gestão; intermitência, precariedade e apagamento são as suas práticas.

Ainda reincidentes, seguem as práticas de cooptação, legitimadas pelo bordão "todos precisam trabalhar", e a consequente estilização da precariedade, quando passamos a ver de perto os riscos de uso da arte como laboratório para as diversas formas de pacificação: bastaria ver a retórica das contra- 
partidas sociais atravessando a exigência de justificativa das artes. De certo modo, a arte era usada para desenhar novos limites, ao mesmo tempo em que se presumia um processo de recomposição de classes no país - pelo menos desde o início dos anos 2000.

Ali onde o teatro intuiu mais decisivamente tal movimento, seus corpos e sua língua foram, por assim dizer, assimilando as marcas dos apagamentos reiterados de nossa história, ou, em seus momentos altos, fazendo ouvir e ver seus fantasmas ainda entre nós.

Nesse mundo habitado por fantasmas, a figura que emerge numa espécie de ritual de exorcismo é o possuído. Aquela figura que se deixou incorporar pelo fantasma de uma revolta narcísica. Segundo algumas crenças, que no contexto atual de regime pentecostal talvez devêssemos levar a sério, ao morrer, alguns espíritos permanecem pairando entre nós, sem saber o rumo, teimando em acertar contas com os vivos, que veem como responsáveis por seus sofrimentos de alma penada. Em revolta permanente, precisam de corpos para fazer ouvir suas exigências. De onde a pergunta urgente: quem são os nossos mortos?

O movimento de possuídos que tem tomado as ruas do país transformou a política nessa prática alucinada de exorcismo prolongado, ritual entre o cômico e o macabro, como aliás reitera o gênero, para o qual um ritmo de suspense vazio deve adiar a solução. Solução essa também entre o previsível e o susto, já que o susto, nesse caso, não se confunde com o espanto, pois segundo as regras desse gênero menor, com seus efeitos de paradoxo rebaixado, é preciso produzir medo, mas medo daquilo que já conhecemos. O fantasma clama por um exorcista, que no entanto colocará à prova, até que o seu destino se cumpra, enviando a alma ao seu endereço final. No ritual de exorcismo é preciso deixar que o fantasma fale, e, para muitos, a sua fala tem poder de revelação. Mas não é preciso ser totalmente cético para saber que um fantasma só pode falar do passado. O tempo da possessão é o da justaposição dos fusos: o presente seria o momento de correção de um passado que não passou. O possuído difere do zumbi; não se trata de um morto-vivo à procura de energia vital e sangue. Ao contrário, muitas vezes, é do fantasma que vem a energia que faltava àquele corpo. O possuído tem sua consciência suspensa, convivendo com a voz-fantasma que o habita. 
Mas é preciso estar atento, pois o ritual uma hora cessa, deve ser interrompido, e o corpo exorcizado quase sempre é também aquele que não recorda. Por outra, pode ser que o exorcista não cumpra todos os seus desígnios, e o risco da série pode levar a continuidades ainda mais escabrosas.

O pensamento não se confunde com exorcismo.

Tudo se passa como se uma parte da sociedade brasileira tivesse adormecido ao estalo de um fuso, lá em 1964, e ao barulho de panelas despertasse cinquenta anos depois, e quisesse... agir, como se estivesse lá, naquela infinda noite de 31 de março, sem saber distinguir entre a realidade e seu sonho noturno. A gesticulação infantilizada quer nos fazer crer que o tempo não passou. Foi isso, aliás, o que apareceu na fala de um deputado, durante a sessão televisionada de legitimação do impedimento, no dia 17 de abril de 2016. Na chanchada sinistra, segundo um procedimento de fusão, a antes torturada era agora a impedida e, ainda outra vez, torturada. Ao elogiar o militar torturador e afirmar que a esquerda, derrotada em 1964, era agora derrotada outra vez, o gesto do deputado revelou-se alegoria fúnebre: 1964 estaria ali, continuando naquele ato, que encenava, em rede nacional, uma sessão de tortura, em nome de um deus e de famílias, expressões privadas da ordem regida pela legião dos "bbbb" - os bancos e suas incorporações, os bois e sua sangria, as balas e seus alvos, a bíblia e suas conversões.

Em grande medida, vivemos hoje uma disputa pelo tempo, plasmada para uns numa luta em torno de narrativas, mas, de fato, numa luta pela vida. O esforço é o de não aderir a nenhuma forma de regressão, e para tanto é preciso estar também alerta às bandeiras levantadas. $O$ risco de entoarmos bordões que nos devolvam ao tempo que devemos fazer passar é da mesma ordem que o risco de adiarmos o levante, porque precisaríamos ainda uma vez negociar.

Nem possessão, nem exorcismo: os mortos, diferentemente dos vivos, querem ser esquecidos. O problema, portanto, está em lidar com os vivos como se esses já estivessem mortos.

Se no teatro o trabalho de lembrança implica um trabalho de reparação, não basta no entanto um olhar reparador ou a emergência de teatralidades marginais: é preciso reinventar o próprio teatro enquanto campo de lutas. 
Se é verdade que a história dos homens é a história da luta de classes, no interior dessa luta há ainda uma outra, pela verdade, que desde o gregos é também uma luta contra as formas do esquecimento.

Da pergunta "quem são os nossos mortos?" emerge a pergunta sobre "quem se recusa a esquecer?".

Um dos maiores empenhos do então governo interino de 2016, logo empossado pela via do putsch jurídico-parlamentar, será o de apagar os vestígios de uma luta, de que o teatro é, sem dúvida, um momento decisivo. O cancelamento do Ministério da Cultura foi a primeira tentativa, e sua retomada não alterou esse desígnio. O que está em jogo nesse movimento é o trabalho de apagamento e a conversão do ministério em seu agente principal. A tarefa da arte, do teatro, não é apenas a de resistir a esse movimento, mas de aprofundar as alianças que até então se esboçavam. Desenhados os limites, eles tendem a explodir.

Para o teatro, essa explosão poderia ser um programa.

O ano de 2016, do qual ainda não saímos, e que pode durar mais do que imaginamos, marca menos rupturas do que continuidades. Diante do quadro de estupor, José Antonio Pasta Júnior, em fala recente ${ }^{2}$, chamou a atenção para a continuidade e a duração do golpe de 1964 na sociedade brasileira, e suas inflexões avassaladoras: a sequência de golpes de reposição. Por um lado, faz pensar sobre aquele alerta de Roberto Schwarz (1978), na "Nota de 1978" ao seu ensaio "Cultura e política, 1964-1969 - alguns esquemas": "o tempo passou e não passou" (p. 61). Por outro lado, faz lembrar as observações de Luiz Roberto Salinas Fortes, em seu Retrato Calado (publicado postumamente, em 1988), que sob o signo da tortura nos anos 1970 se interrogava:

\footnotetext{
Não teria havido, a partir de determinado momento, a "esquadronização" geral, uma institucionalização nacional daqueles métodos que apenas começavam a ser utilizados, agora, também para os que ousavam erguer-se contra o regime? (SALINAS, 2012, p. 40)
}

2 Por ocasião do ciclo de debates Arte e realidade, promovido pelo grupo Tablado de Arruar e Sesc Ipiranga, em mesa intitulada "Literatura, cinema e golpe", ocorrida em 16 de julho de 2016, e da qual participou também o crítico e professor Ismail Xavier. 
Mas o teatro é tomado também agora por essa luta contra todas as formas de reação e destruição da política como dissenso e transformação. Trata-se de fazer emergir, no combate às regras da exceção, verdadeiras poéticas de emergência. Como escrevia Antonio Candido em 1943 (2002):

Porque há para todos nós um problema sério, tão sério que nos leva às vezes a procurar meio afoitamente uma "solução": a buscar uma regra de conduta, custe o que custar. Este problema é o do medo. Do medo que nos toma a todos de estarmos sendo inferiores à nossa tarefa; ou de não conseguirmos fazer algo de definitivamente útil para o nosso tempo [...]. Você tem algum critério para afastar o medo? Eu não posso bem dizer que tenha, mas confesso que esse combate a todas as formas de Reação [...] nos ajudaria muito a ficar livres dele. (p. 249-250)

Longe, todavia, de "podermos dormir em paz".

\section{Referências bibliográficas}

ARANTES, O. B. F.; ARANTES, P. Sentido da Formação: três estudos sobre Antonio Candido, Gilda de Melo e Souza e Lúcio Costa. Rio de Janeiro: Paz e Terra, 1997. ARANTES, P. Extinção. São Paulo: Boitempo, 2007.

Sentimento da dialética na experiência intelectual brasileira: dialética e dualidade segundo Antonio Candido e Roberto Schwarz. Rio de Janeiro: Paz e Terra, 1992.

O novo tempo do mundo: e outros estudos sobre a era da emergência. São Paulo: Boitempo, 2014.

Zero à esquerda. São Paulo: Conrad, 2004.

AZEVEDO, J. F. de. O processo teatro (notas para um programa de trabalho). In: ARAÚJO, A.; AZEVEDO, J. F. de; TENDLAU, M. (Orgs.). Próximo Ato: teatro de grupo. São Paulo: Itaú Cultural, 2011.

AZEVEDO, J. F. de. Uma trajetória na intermitência (notas à procura de um esquema). In: DESGRANGES, F.; LEPIQUE, M. (Orgs.). Teatro e vida pública. São Paulo: Hucitec; Cooperativa Paulista de Teatro, 2012.

CANDIDO, A. Plataforma da nova geração. In: DANTAS, V. Textos de intervenção.

Seleção, apresentação e notas de Vinicius Dantas. São Paulo: Duas Cidades; Editora 34, 2002.

COSTA, I. C. A hora do teatro épico. Rio de Janeiro: Paz e Terra, 1996.

. Nem uma lágrima: teatro épico em perspectiva dialética. São Paulo: Expressão Popular; Nankin, 2012. 
COSTA, I. C.; AZEVEDO, J. F. de. Duas histórias do teatro brasileiro. Revista Vintém: teatro e cultura brasileira, São Paulo, n. 3, p. 29-37, 1999.

FERNANDES, S. Grupos teatrais: anos 70. São Paulo: Unicamp, 2000.

GARCIA, S. Teatro da militância: a intenção do popular no engajamento político. São Paulo: Perspectiva; Edusp, 1990.

GOMES, P. E. S. Cinema: trajetória no subdesenvolvimento. Rio de Janeiro: Paz e Terra, 1980.

OLIVEIRA, F. de. Política numa era de indeterminação: opacidade e reencantamento. In: OLIVEIRA, F.; RIZEK, C. S. A era da indeterminação. São Paulo: Boitempo, 2007. p. 15-45.

PASTA JÚNIOR, J. A. Formação supressiva: constantes estruturais do romance brasileiro. Tese (Livre docência na área de literatura brasileira) - Faculdade de FiIosofia, Letras e Ciências Humanas, Universidade de São Paulo, São Paulo, 2011. PRADO, D. de A. O teatro brasileiro moderno. São Paulo: Perspectiva; Edusp, 1988. PRADO, D. de A. Teatro em progresso: crítica teatral (1955-1964). São Paulo: Martins, 1964.

SALINAS FORTES, L. R. Retrato Calado. São Paulo: Cosac Naify, 2012.

SCHWARZ, R. Cultura e Política, 1964-1969. In: O pai de família e outros estudos. Rio de Janeiro: Paz e Terra, 1978. p. 61-92.

SCHWARZ, R. Sequências brasileiras: ensaios. São Paulo: Companhia das Letras, 1999.

Recebido em 12/09/2016

Aprovado em 05/11/2016

Publicado em 21/12/2016 